Q

updates

Cite as

Nano-Micro Lett.

(2020) 12:161

Received: 19 May 2020

Accepted: 9 July 2020

Published online: 11 August 2020

(C) The Author(s) 2020

\title{
In Situ Electrochemical Mn(III)/Mn(IV) Generation of Mn(II)O Electrocatalysts for High-Performance Oxygen Reduction
}

\author{
Han Tian ${ }^{1,2}$, Liming Zeng ${ }^{4}$, Yifan Huang ${ }^{5}$, Zhonghua $\mathrm{Ma}^{6}$, Ge Meng ${ }^{1,2}$, Lingxin Peng ${ }^{1,2}$, \\ Chang Chen ${ }^{1,2}$, Xiangzhi Cui ${ }^{1,2,3} \bowtie$, Jianlin Shi ${ }^{1,2} \bowtie$ \\ $\square$ Xiangzhi Cui, cuixz@mail.sic.ac.cn; Jianlin Shi, jlshi@mail.sic.ac.cn \\ 1 State Key Lab of High Performance Ceramics and Superfine Microstructure, Shanghai Institute \\ of Ceramics, Chinese Academy of Sciences, Shanghai 200050, People's Republic of China \\ 2 Center of Materials Science and Optoelectronics Engineering, University of Chinese Academy of Sciences, \\ Beijing 100049, People's Republic of China \\ 3 School of Chemistry and Materials Science, Hangzhou Institute for Advanced Study, University of Chinese \\ Academy of Sciences, Hangzhou 310021, People's Republic of China \\ 4 College of Chemistry and Molecular Sciences, Hubei Key Lab of Electrochemical Power Sources, Wuhan \\ University, Wuhan 430072, People's Republic of China \\ 5 Wuhan University of Science and Technology, Wuhan 430081, People's Republic of China \\ 6 College of Material Science and Engineering, Donghua University, Shanghai 201620, \\ People's Republic of China
}

\section{HIGHLIGHTS}

- $\mathrm{MnO}$ rich in oxygen vacancies has been synthesized.

- The synthesized $\mathrm{MnO}$ demonstrates excellent oxygen reduction reaction performance and high output power in $\mathrm{Zn}$-air battery.

- The high catalytic activity is attributed to the synergetic catalytic effect between oxygen vacancies and in situ generated $\mathrm{Mn}^{3+} / \mathrm{Mn}^{4+}$.

\begin{abstract}
Among various earth-abundant and noble metal-free catalysts for oxygen reduction reaction (ORR), manganese-based oxides are promising candidates owing to the rich variety of manganese valence. Herein, an extremely facile method for the synthesis of cubic and orthorhombic phase coexisting $\mathrm{Mn}(\mathrm{II}) \mathrm{O}$ electrocatalyst as an efficient ORR catalyst was explored. The obtained MnO electrocatalyst with oxygen vacancies shows a significantly elevated ORR catalytic activity with a half-wave potential $\left(E_{1 / 2}\right)$ of as high as $0.895 \mathrm{~V}$, in comparison with that of commercial Pt/C $\left(E_{1 / 2}=0.877 \mathrm{~V}\right)$. More impres-
\end{abstract}

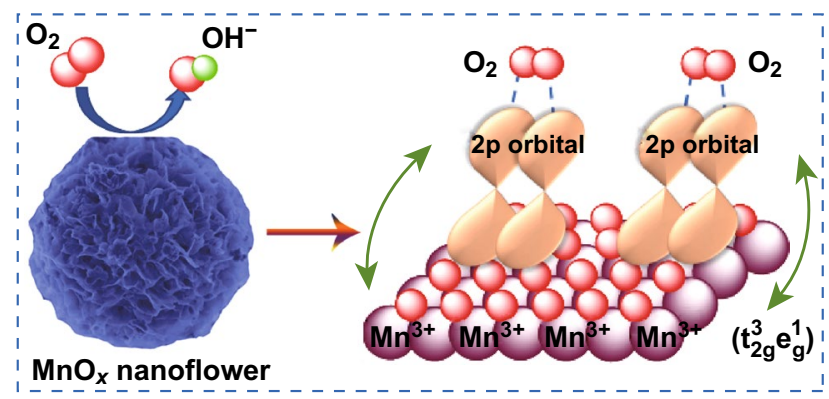
sively, the $\mathrm{MnO}$ electrocatalyst exhibits a marked activity enhancement after test under a constant applied potential for $1000 \mathrm{~s}$ thanks to the in situ generation and stable presence of high-valence manganese species $\left(\mathrm{Mn}^{3+}\right.$ and $\left.\mathrm{Mn}^{4+}\right)$ during the electrochemical process, initiating a synergetic catalytic effect with oxygen vacancies, which is proved to largely accelerate the adsorption and reduction of $\mathrm{O}_{2}$ molecules favoring the ORR activity elevation. Such an excellent ORR catalytic performance of this MnO electrocatalyst is applied in $\mathrm{Zn}$-air battery, which shows an extra-high peak power density of $63.2 \mathrm{~mW} \mathrm{~cm}^{-2}$ in comparison with that $\left(47.4 \mathrm{~mW} \mathrm{~cm}^{-2}\right)$ of commercial $\mathrm{Pt} / \mathrm{C}$ under identical test conditions.

KEYWORDS Zinc-air battery; In situ generation; High-valence manganese species; Synergetic catalytic effect 


\section{Introduction}

Advanced energy storage and conversion systems, such as fuel cells and metal-air batteries, are attracting more and more attentions worldwide due to the ever-increasing fossil energy consumption and accompanying severe environmental problems [1,2]. Great progresses have been made in metal-air batteries (especially Zn-air battery) thanks to the simplicity in cell structure and operation [3, 4], and more importantly, the opportunities of employing a large variety of noble metal-free catalysts. However, the thermodynamically sluggish oxygen reduction reaction (ORR) kinetics and severe energy efficiency losses during the cell operation remain the main obstacles for the commercialization of this kind of metal-air batteries [5-7]. To date, platinum (Pt) and Pt-based catalysts are still the most commonly used electrocatalysts for ORR, while the high cost and scarcity of Pt have been greatly hindering their scale-up application in Zn-air battery [8-10]. Hence, the development of cost-effective catalysts with satisfactory ORR activity without using Pt or other noble metals is the key subject of this field [11].

Transition metal oxides are highly promising candidates for ORR electrocatalysis due to their electronic properties in the d-state, which greatly influence the electrocatalytic activity by changing d-orbital electrons number [12]. Various oxidation states of transition metals enable the electrons transfer among the metal ions, thus contributing to their excellent ORR performances [13]. Among these transition metal oxides, manganese oxides have induced huge interests owing to its abundance, low cost, non-toxic and its various valence states (I-VI) $[14,15]$. However, the large variety of Mn valence complicates the detailed electrocatalytic mechanism study and impedes further practical application. There are more than 20 polymorphs for manganese oxides [16], and their diverse chemical compositions, crystalline structures and microstructure such as morphologies and pore structures, etc., are of significance or even critical importance in affecting the catalytic activity of $\mathrm{MnO}_{x}$ [17]. Actually, the crystalline structures of manganese oxides are determined by the connection types between the $\left[\mathrm{MnO}_{6}\right]$ units via sharing corners or edges. Bixbyite $\alpha-\mathrm{Mn}_{2} \mathrm{O}_{3}$ is composed of corner-sharing $\left[\mathrm{MnO}_{6}\right]$ octahedra [18], and a part of which will have longer apical bonds due to Jahn-Teller distortion. The layered $\delta-\mathrm{MnO}_{2}$ has $\left[\mathrm{MnO}_{6}\right]$-shared edges in each layer with a variety of alkaline metal cations in between the layers, while different isomers of $\mathrm{MnO}_{2}$ with one-dimensional tunnel structures have varied tunnel sizes, such as $2 \times 2$ tunnels for $\alpha-\mathrm{MnO}_{2}, 1 \times 1$ tunnels for $\beta-\mathrm{MnO}_{2}$ and $1 \times 2$ and $1 \times 1$ tunnels for $\gamma-\mathrm{MnO}_{2}$ [19]. Suib and coworkers synthesized a series of manganese oxides including $\alpha-, \beta-, \delta-\mathrm{MnO}_{2}$ and amorphous $\mathrm{MnO}_{2}$ (AMO) via facile methods and demonstrated that the electrocatalytic activities follow the order of $\alpha-\mathrm{MnO}_{2}>\mathrm{AMO}>\beta-\mathrm{MnO}_{2}>\delta-\mathrm{MnO}_{2}$ [20]. However, the electrocatalytic activities of manganese oxides are still not satisfactory because of the poor intrinsic activity and conductivity impeding the electron transfer during the ORR process, which could be enhanced by the introduction of oxygen vacancies and carbon matrix [21].

Herein, we demonstrate the fabrication of a novel Mn(II) $\mathrm{O}$ electrocatalyst with superior ORR performance via a facile "two-step" approach of $\mathrm{Mn}_{3} \mathrm{O}_{4}$ synthesis and subsequent heat treatment at varied temperatures under the reducing atmosphere. It has been found that $\mathrm{MnO}$ obtained by the treatment at $600{ }^{\circ} \mathrm{C}$ shows the highest ORR electrocatalytic activity of $0.895 \mathrm{~V}$ in half-wave potential $\left(E_{1 / 2}\right)$, which is $18 \mathrm{mV}$ higher than that of commercial Pt/C $\left(E_{1 / 2}=0.877 \mathrm{~V}\right)$. More impressively, the ORR activity further demonstrates a significant enhancement during the long-term electrochemical test because of the in situ generation and stable existence of higher valence species in the form of $\mathrm{Mn}_{5} \mathrm{O}_{8}$, i.e., $2 \mathrm{Mn}_{2} \mathrm{O}_{3} \cdot \mathrm{MnO}_{2}$. The production of $\mathrm{Mn}^{3+}$ and $\mathrm{Mn}^{4+}$ is responsible for the obviously enhanced $\mathrm{O}_{2}$ transformation ability and peroxide decomposition, respectively, further confirming that the presence of $\mathrm{Mn}^{3+} / \mathrm{Mn}^{4+}$ in a ratio of 2:1 in the present case is vital for the high ORR activity of $\mathrm{MnO}$.

\section{Experimental Section}

\subsection{Materials}

Manganese (III) acetylacetonate $\left(\mathrm{C}_{15} \mathrm{H}_{21} \mathrm{MnO}_{6}, 98 \%+\right)$ was purchased from Adamas Reagent Co., Ltd. Absolute ethyl alcohol was purchased from Shanghai Lingfeng Chemical Reagent Co., Ltd. Nafion D-520 dispersion (5 wt\%) was purchased from Dupont China Holding Co., Ltd. Commercial $20 \mathrm{wt} \% \mathrm{Pt} / \mathrm{C}$ and the carbon black (XC-72) were purchased from Shanghai HEPHAS Energy Equipment Co., Ltd. All materials were used as received without further purification. 


\subsection{Synthesis of $\mathrm{Mn}_{3} \mathrm{O}_{4}$}

The $\mathrm{Mn}_{3} \mathrm{O}_{4}$ sample was synthesized by the hydrothermal method. First, $1 \mathrm{mM}$ of manganese acetylacetonate was dissolved in $40 \mathrm{~mL}$ of absolute ethyl alcohol. Second, the solution was transferred into an $80 \mathrm{~mL}$ Teflon reaction kettle and was heated at $120{ }^{\circ} \mathrm{C}$ for $10 \mathrm{~h}$. Third, the as-obtained mixture was washed with ethyl alcohol for three times and then washed with deionized water for one time by the centrifugal separation. Finally, the prepared powder was collected after the freeze drying for $12 \mathrm{~h}$.

\subsection{Synthesis of $\mathrm{MnO}$}

The as-obtained $\mathrm{Mn}_{3} \mathrm{O}_{4}$ powder was thermal treated to obtain the final $\mathrm{MnO}$ electrocatalyst at varied temperatures $\left(400,500,550,600\right.$ and $\left.700{ }^{\circ} \mathrm{C}\right)$ for $2 \mathrm{~h}$ in reducing gas flow (containing $5 \mathrm{vol} \%$ hydrogen and $95 \mathrm{vol} \%$ argon) in the tube furnace with the heating rate is $5{ }^{\circ} \mathrm{C} \mathrm{min}^{-1}$. Among all samples, it has been found that $600{ }^{\circ} \mathrm{C}$ is the optimal treatment temperature for the highest catalytic activity.

\subsection{Materials Characterization}

The powder X-ray diffraction (XRD) patterns were acquired on a Rigaku D/Max-2550 V X-ray diffractometer with a $\mathrm{Cu}$ $\mathrm{K}_{\alpha}$ radiation target $(40 \mathrm{kV}, 40 \mathrm{~mA})$ at a scan rate of $\left(4^{\circ}\right)$ $\min ^{-1}$. X-ray photoelectron spectroscopy (XPS) signals were measured on a Thermo Fisher Scientific ESCAlab250 XPS instrument with monochromatic $\mathrm{Al} \mathrm{K}_{\alpha} \mathrm{X}$-rays. Binding energies of high-resolution spectra were measured after calibration, specifically, by setting C $1 s$ at $284.6 \mathrm{eV}$. Spherical aberration-corrected HAADF-STEM measurements were taken on a JEM-ARM300F instrument (Shanghai Institute of Microsystem and Information Technology). Scanning electron microscope (SEM) imaging was carried out using a FEI Magellan-400 field emission scanning electron microscopy $(5 \mathrm{kV})$. Transmission electron microscopy (TEM) patterns were collected using a JEM-2100F field emission transmission electron microscopy $(200 \mathrm{kV})$. Electron spin resonance (ESR) signals were measured on a Bruker A300 ESR instrument.

\subsection{Electrochemical Measurements}

The electrochemical measurements were carried out in $1 \mathrm{M}$ $\mathrm{KOH}$ solution by a $\mathrm{CH}$ Instruments $760 \mathrm{E}$ electrochemical workstation using a standard three-electrode setup. During ORR test, a glassy carbon electrode (GCE) coated with catalysts, an $\mathrm{Ag} / \mathrm{AgCl}$ electrode and a graphite rod were employed as the working electrode, reference electrode and counter electrode, respectively. $\mathrm{The} \mathrm{Ag} / \mathrm{AgCl}$ electrode was stored in $3 \mathrm{M} \mathrm{KCl}$ solution and rinsed with deionized water before use. All potentials were calibrated relative to the reversible hydrogen electrode (RHE) scale according to the Nernst equation $\left(E_{\mathrm{RHE}}=E_{\mathrm{Ag} / \mathrm{AgCl}}+0.059 \times \mathrm{pH}+0.209 \mathrm{~V}\right)$, where $E_{\mathrm{Ag} / \mathrm{AgCl}}$ is the external potential measured against the $\mathrm{Ag} / \mathrm{AgCl}$ reference electrode, which has been corrected with a reversible hydrogen electrode.

To prepare catalyst ink for ORR test, $5 \mathrm{mg}$ catalyst, $5 \mathrm{mg}$ carbon black and $10 \mu \mathrm{L}$ of Nafion were dispersed in $900 \mu \mathrm{L}$ of isopropanol and $90 \mu \mathrm{L}$ of deionized water. Similarly, the commercial $\mathrm{Pt} / \mathrm{C}$ ink was prepared by dispersing $10 \mathrm{mg}$ catalyst in a solution containing $10 \mu \mathrm{L}$ of Nafion, $900 \mu \mathrm{L}$ of isopropanol and $90 \mu \mathrm{L}$ of deionized water. After the mixture was sonicated for $30 \mathrm{~min}, 10 \mu \mathrm{L}$ of homogeneous ink was pipetted onto the glassy carbon electrode. Before all electrochemical measurements, high-purity $\mathrm{N}_{2} / \mathrm{O}_{2}$ gas was bubbled into the solution for at least $30 \mathrm{~min}$. The cyclic voltammetric (CV) measurements were performed in $1 \mathrm{M} \mathrm{O}_{2}$-saturated $\mathrm{KOH}$ solution at a scan rate of $100 \mathrm{mV} \mathrm{s}^{-1}$. Then, the linear sweep voltammetric (LSV) curves were measured in $1 \mathrm{M}$ $\mathrm{O}_{2}$-saturated $\mathrm{KOH}$ solution at a scan rate of $10 \mathrm{mV} \mathrm{s}^{-1}$ at a rotating speed of $1600 \mathrm{rpm}$. Besides, the electrochemical impedance spectroscopy (EIS) measurements were conducted in a frequency range of $10^{-2}$ to $10^{5} \mathrm{~Hz}$ with an amplitude of $5 \mathrm{mV}$ at a fixed voltage of $0.965 \mathrm{~V}$ (vs. RHE).

The kinetics parameters including electron transfer number $(n)$ and the yield of $\mathrm{H}_{2} \mathrm{O}_{2}$ can be calculated from the following Eqs. (1) and (2).

$$
\begin{aligned}
& n=\frac{4 I_{\mathrm{D}}}{I_{\mathrm{D}}+I_{\mathrm{R}} / N} \\
& \% H_{2} O_{2}=\frac{200 I_{\mathrm{R}} / N}{I_{\mathrm{D}}+I_{\mathrm{R}} / N}
\end{aligned}
$$


where $I_{\mathrm{D}}$ and $I_{\mathrm{R}}$ are the disk current and the ring current, respectively, and $N$ is the experimental current collection efficiency by Pt ring on the ring-disk electrode, generally determined to be the value of 0.37 from the reduction of $\mathrm{K}_{3} \mathrm{Fe}(\mathrm{CN})_{6}$.

The electrochemical active surface areas of the electrode were calculated according to the Randles-Sevcik equation (Eq. (3)) [22, 23]:

$I_{\mathrm{p}}=\left(2.69 \times 10^{5}\right) n^{3 / 2} A C * D^{1 / 2} v^{1 / 2}$

where $I_{\mathrm{p}}$ refers to the cathodic peak current, $n$ is the total number of electrons transferred $(n=4), A$ is the effective surface area of the electrode, $D$ is the diffusion coefficient for $\mathrm{KOH}=1.9 \times 10^{-5} \mathrm{~cm} \mathrm{~S}^{-1}, C^{*}$ is the concentration of $\mathrm{KOH}$, and $v$ is the scan rate.

\subsection{Zinc-Air Battery Measurements}

To prepare catalyst ink for zinc-air battery test, $6 \mathrm{mg}$ catalyst, $2 \mathrm{mg}$ carbon black and $10 \mu \mathrm{L}$ of Nafion were dispersed in $900 \mu \mathrm{L}$ of isopropanol and $90 \mu \mathrm{L}$ of deionized water. Similarly, the commercial Pt/C catalyst ink was prepared by dispersing $6 \mathrm{mg}$ catalyst in a solution containing $10 \mu \mathrm{L}$ of Nafion, $900 \mu \mathrm{L}$ of isopropanol and $90 \mu \mathrm{L}$ of deionized water. After the mixture was sonicated for $30 \mathrm{~min}$, the as-prepared ink was pipetted onto a carbon paper substrate (the loading amount: $2 \mathrm{mg} \mathrm{cm}^{-2}$ ) as zinc-air battery cathode. A polished $\mathrm{Zn}$ foil was applied as the anode, and $6 \mathrm{M} \mathrm{KOH}$ filled with $0.2 \mathrm{M} \mathrm{Zn}(\mathrm{Ac})_{2}$ was applied as the electrolyte to form zincate $\left(\mathrm{Zn}(\mathrm{OH})_{4}^{2-}\right)$ to ensure reversible $\mathrm{Zn}$ electrochemical reactions at the anode. The polarization curves of zinc-air battery were recorded by a $\mathrm{CH}$ Instruments $760 \mathrm{E}$ electrochemical workstation using a standard three-electrode setup.

\section{Results and Discussion}

\subsection{Catalyst Synthesis and Characterization}

The schematic diagram of $\mathrm{MnO}$ synthesis is shown in Fig. 1a. First, the flower-like $\mathrm{Mn}_{3} \mathrm{O}_{4}$ nanosheets assemblies were readily prepared via hydrothermal treatment, which is kind of spinel oxides with mixed $\mathrm{Mn}^{3+}$ and $\mathrm{Mn}^{2+}$ valences at the tetrahedral and octahedral sites, respectively [24]. Second, the $\mathrm{MnO}$ electrocatalyst was obtained by the thermalreduction of pre-synthesized $\mathrm{Mn}_{3} \mathrm{O}_{4}$ at varied temperatures $\left(400,500,550,600\right.$ and $\left.700{ }^{\circ} \mathrm{C}\right)$ under mixed gas flow of 5 vol\% hydrogen and 95 vol\% argon. From the powder XRD patterns (Fig. 1c), MnO exists in the forms of both cubic (PDF\#07-0230) and orthorhombic phase structures (PDF\#04-0326). Furthermore, the intensities of diffraction peaks of $\mathrm{MnO}$ electrocatalyst clearly increase along with the increase in reduction temperature owing to the enhanced crystallinity. After measured in $1 \mathrm{M} \mathrm{O}_{2}$-saturated $\mathrm{KOH}$ solution for 1000 and 2000 cycles as ORR electrocatalyst, the sample MnO-600 displayed in Fig. S1 shows atypical XRD pattern of monoclinic phase $\mathrm{Mn}_{5} \mathrm{O}_{8}$, i.e., $2 \mathrm{Mn}_{2} \mathrm{O}_{3} \cdot \mathrm{MnO}_{2}$ (PDF\#39-1218), which reveals the generation and coexistence of Mn(III) and Mn(IV) in the catalyst (Fig. 1b) [25].

The scanning (SEM, Fig. 2a) and the transmission electron microscopic (TEM, Fig. 2b) images also demonstrate the successful synthesis of $\mathrm{Mn}_{3} \mathrm{O}_{4}$ nanoflowers composed of a large amount of nanosheets. After the reduction treatment at $600{ }^{\circ} \mathrm{C}$, these nanosheets are evolved into numerous tiny nanoparticles (Fig. 2c, d). It can also be found that several big bulks appear due to the inevitable drastic grain growth during treatment at elevated temperatures. Nevertheless, as shown in Figs. S2-S4, the nanoflowers' skeleton structures are well preserved in a wide range of temperatures (400-700 ${ }^{\circ} \mathrm{C}$ ), which confirms the morphological stability of the $\mathrm{MnO}_{x}$ nanoflowers. In order to further prove the structure stability under electrochemical test conditions, the SEM and TEM images of MnO-600 after 1000 and 2000 ORR cycles are shown in Figs. 2e, f and S5, respectively, and it can be seen that there is no significant structure change after the test. Furthermore, the lattice fringes in spherical aberration-corrected TEM image (Fig. 2g) can be found with the measured interplanar spacings being $0.259 \mathrm{~nm}$ and $0.503 \mathrm{~nm}$ corresponding to the (111) planes of cubic $\mathrm{MnO}$ and (020) planes of orthorhombic $\mathrm{MnO}$, respectively, consolidating the mixed cubic and orthorhombic phase structure of the sample $\mathrm{MnO}-600$. In the meantime, the elemental mapping images of MnO-600 shown in Fig. 2h confirm the highly homogeneous dispersion of $\mathrm{Mn}$ and $\mathrm{O}$ elements.

The large variety of Mn valence makes the structural and property investigation complicated. To clearly reveal the relationship between Mn valence and electrochemical performance, XPS measurements were performed to confirm the surface elemental composition of the catalysts. The survey spectra (Fig. S6) of $\mathrm{Mn}_{3} \mathrm{O}_{4}$ and $\mathrm{MnO}-\mathrm{T}$ catalysts show clearly the peaks centered at around 530 and $640 \mathrm{eV}$, corresponding to $\mathrm{O} 1 s$ and $\mathrm{Mn} 2 p$, respectively. Figure 

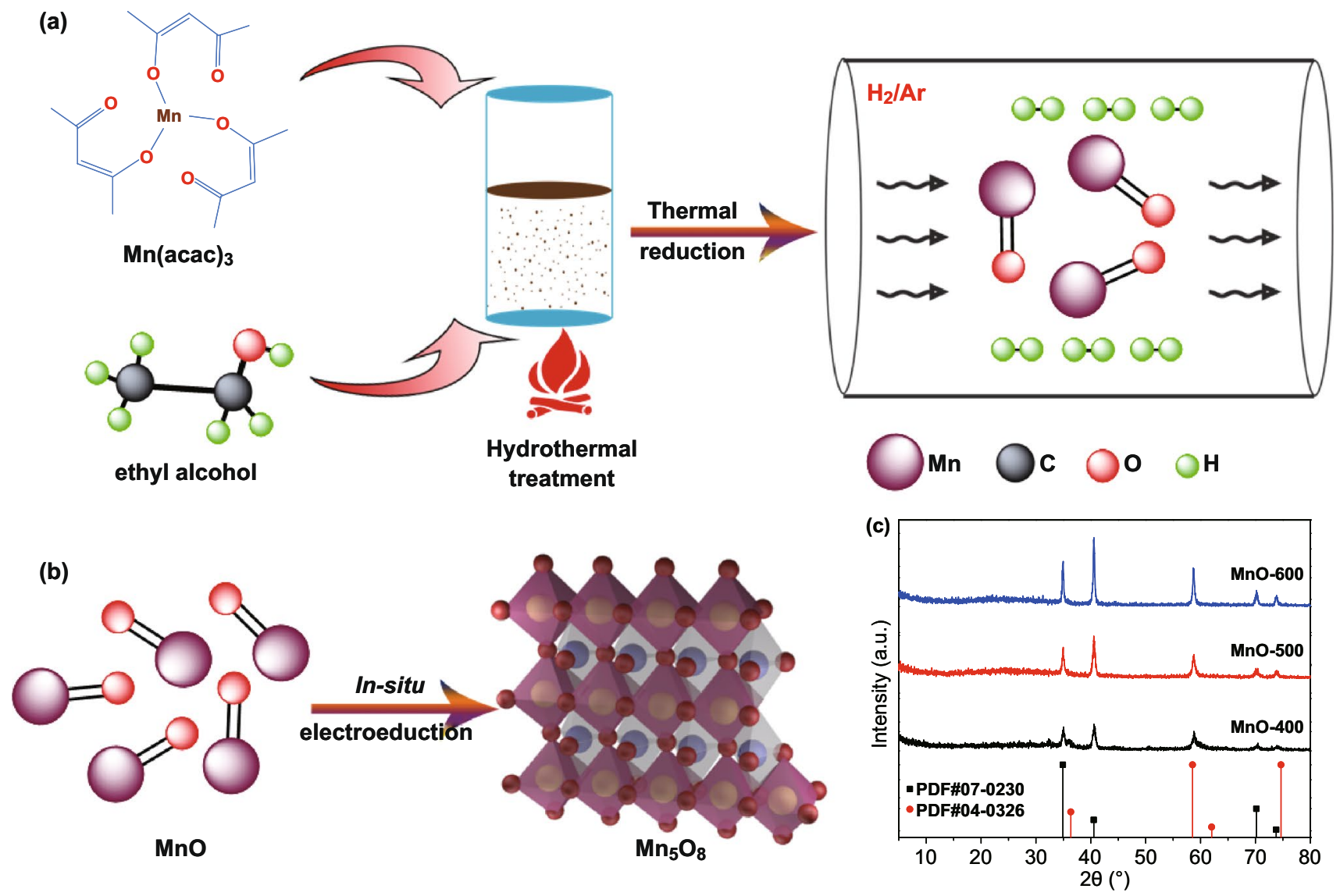

Fig. 1 a Schematic illustration of the synthesis of MnO samples. b Structural evolution schematics of $\mathrm{MnO}_{x}$. $\mathbf{c}$ XRD patterns of MnO-T samples $\left(T=400,500,600{ }^{\circ} \mathrm{C}\right)$

S7 shows the XPS Mn $2 p$ spectra of $\mathrm{Mn}_{3} \mathrm{O}_{4}$ sample. The Mn $2 p_{1 / 2}$ and $2 p_{3 / 2}$ peaks of pre-synthesized $\mathrm{Mn}_{3} \mathrm{O}_{4}$ are at 653.05 and $641.16 \mathrm{eV}$, respectively, which is consistent with the previous reports [26]. As shown in Fig. S8, its binding energy values at 529.98 and $531.74 \mathrm{eV}$ are attributed to the metal-oxygen bonding (O1) and surface oxygen defect sites (O2), respectively [27]. Besides, the comparison of XPS O $1 s$ spectra among different MnO-T catalysts is shown in Fig. 3a. As the temperature gradually increases from 400 to $600{ }^{\circ} \mathrm{C}$, the intensity ratio of $\mathrm{O} 1$ to $\mathrm{O} 2$ peak largely increases from 0.223 to 1.506 , meaning an enhanced content of oxygen vacancies produced at elevated temperatures. The specific $\mathrm{O} 1 / \mathrm{O} 2$ concentrations and the intensity ratio of $\mathrm{O} 1$ to $\mathrm{O} 2$ are displayed in Fig. $3 \mathrm{~b}$ and Table S1.

The comparisons of XPS Mn $2 p$ spectra among MnO-T $\left(T=400,500\right.$ and $600{ }^{\circ} \mathrm{C}$ ) catalysts are displayed in Fig. 3c, and the corresponding binding energy values are listed in Table S2. After the heat treatment at $400{ }^{\circ} \mathrm{C}, \mathrm{Mn} 2 p_{1 / 2}$ and
$2 p_{3 / 2}$ peaks shifted toward higher binding energy, which is due to the partial decomposition of spinel-structural $\mathrm{Mn}_{3} \mathrm{O}_{4}$ and the formation of $\mathrm{Mn}_{2} \mathrm{O}_{3}$ (III) and $\mathrm{MnO}$ (II) mixture. As the reduction temperature was elevated to $500{ }^{\circ} \mathrm{C}$, two peaks further shifted toward higher binding energy owing to the higher reduction degree and more significant spinel-structure decomposition. However, when the reduction temperature was raised to $600{ }^{\circ} \mathrm{C}$, the binding energies of two characteristic peaks began to decrease due to the disappearance of $\mathrm{Mn}^{3+}$, only pure $\mathrm{MnO}$ phase remained at this moment.

To further study how the Mn valences in manganese oxides influence the electrochemical performance of catalysts, XPS spectra of MnO-600 after 1000 and 2000 cycles of ORR tests are obtained and displayed in Fig. 3d. Compared with the pristine $\mathrm{MnO}$ samples, the corresponding binding energy values of $\mathrm{Mn} 2 p_{1 / 2}$ and $2 p_{3 / 2}$ peaks for the samples after the 1000 cycles are obviously enhanced owing to the in situ generation of high-valence $\mathrm{Mn}$ ions $\mathrm{CM}^{3+}$ and 

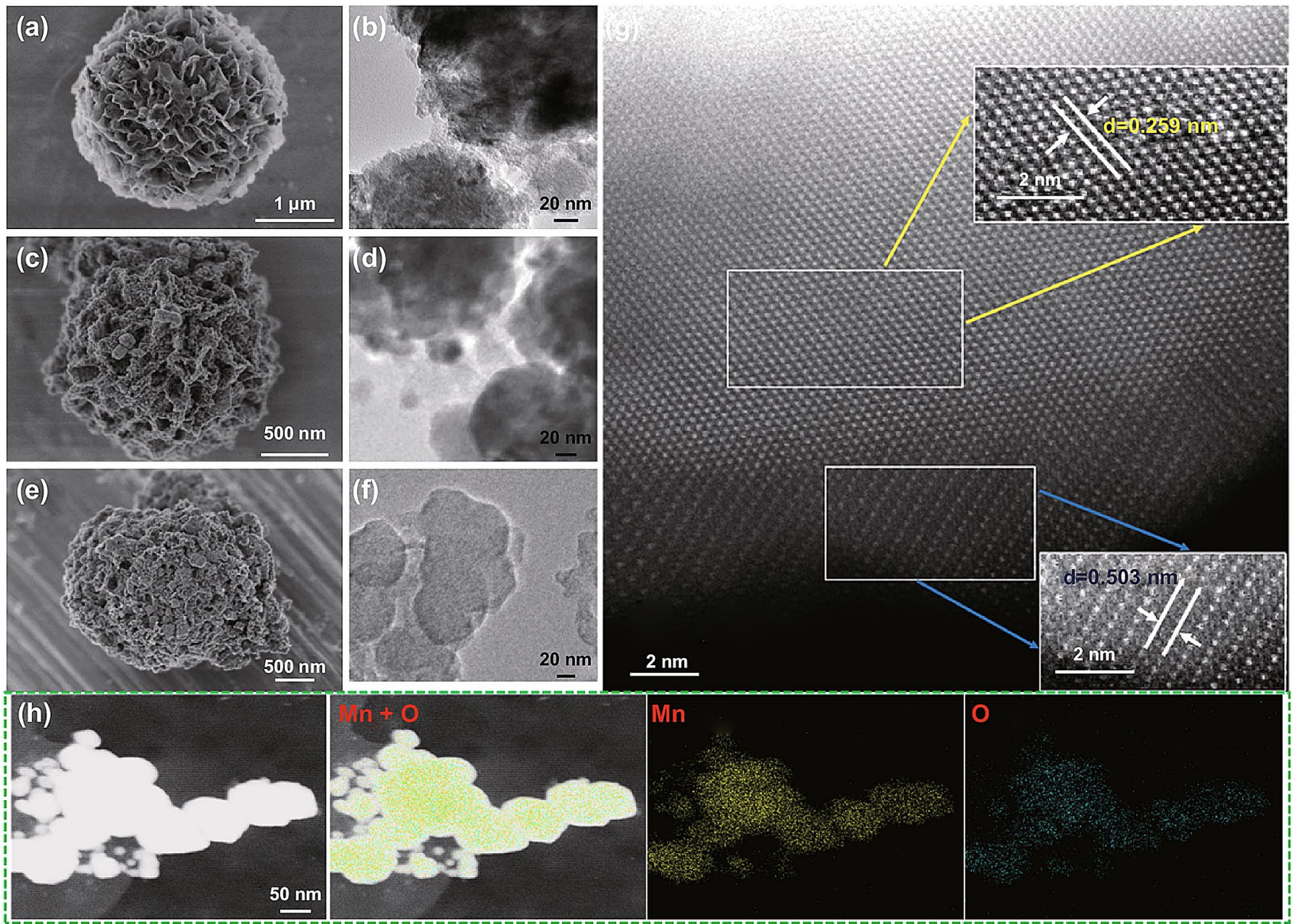

$2 \mathrm{~nm}$
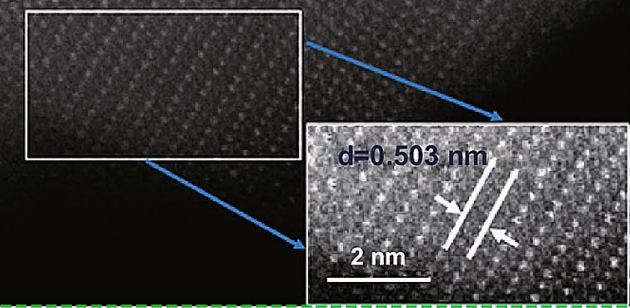

Mn
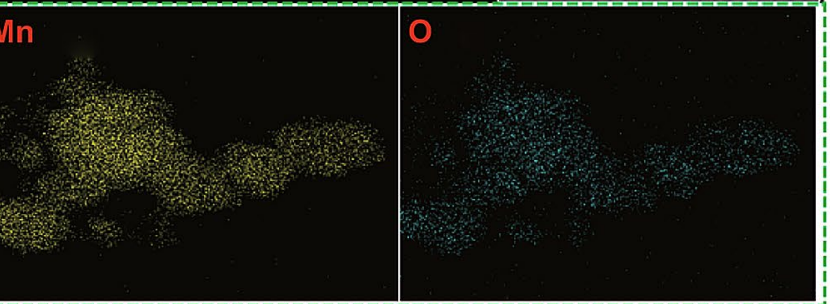

Fig. 2 a, c, e SEM and b, d, f TEM images of $\mathrm{Mn}_{3} \mathrm{O}_{4}$ sample $(\mathbf{a}, \mathbf{b})$, original MnO-600 catalyst $(\mathbf{c}, \mathbf{d})$ and the correspondingly tested MnO-600 catalyst for 2000 ORR cycles $(\mathbf{e}, \mathbf{f})$. g, h Spherical aberration-corrected TEM (g) and TEM-EDS elemental mappings (h) images of MnO-600 sample

$\mathrm{Mn}^{4+}$ ), which is consistent with the XRD result of the formation of $\mathrm{Mn}_{5} \mathrm{O}_{8}$. Then, the $\mathrm{Mn} 2 p_{1 / 2}$ and $2 p_{3 / 2}$ peaks continue to shift toward higher binding energy levels of 653.96 and $642.3 \mathrm{eV}$ (as shown in the data of Table S3), respectively, thanks to the further increase in high-valence Mn ion content after 2000 cycles, which is still in accordance with those of $\mathrm{Mn}^{3+}$ and $\mathrm{Mn}^{4+}$ mixture in the previous report [28]. In summary, the XRD patterns and XPS survey spectra all confirm the production of $\mathrm{Mn}_{5} \mathrm{O}_{8}\left(2 \mathrm{Mn}_{2} \mathrm{O}_{3} \cdot \mathrm{MnO}_{2}\right)$ phase during ORR tests.

Besides, the electron spin resonance (ESR) measurements were adopted to further verify the existence of oxygen vacancies and the variation of Mn valence. As shown in Fig. 3e, all samples show the resonance peaks at the g value of 2.003 attributed to oxygen vacancies [29], and the relative peak intensity increases gradually along with the increase in heat treatment temperature indicating the formation of more amount of oxygen vacancies, which is in accordance with the previous XPS results (Fig. 3a). More importantly, ESR technique is commonly used for valence analysis of transition metals and rare-earth elements owing to the incomplete occupied electron orbitals $(3 d, 4 d, 5 d, 4 f \ldots)$ and lone pair electrons. Generally, $\mathrm{Mn}^{5+}$ ions without lone pair electron display no ESR signal, whereas $\mathrm{Mn}^{2+}$ ions with three lone pair electrons show a typical sextet ESR pattern [30]. It can be found that all samples in Fig. 3f display such sextet patterns $(g=2.00624$, Aiso $=96.5 \mathrm{G})$ and the higher intensity sextet indicates the larger portion of $\mathrm{Mn}^{2+}$ in samples. As the reduction temperature reaches $600^{\circ} \mathrm{C}$, the $\mathrm{MnO}-600 \mathrm{sam}$ ple shows the highest intensity sextet signals among ESR measurements, indicating the largest amount of $\mathrm{Mn}^{2+}$ in the material. 

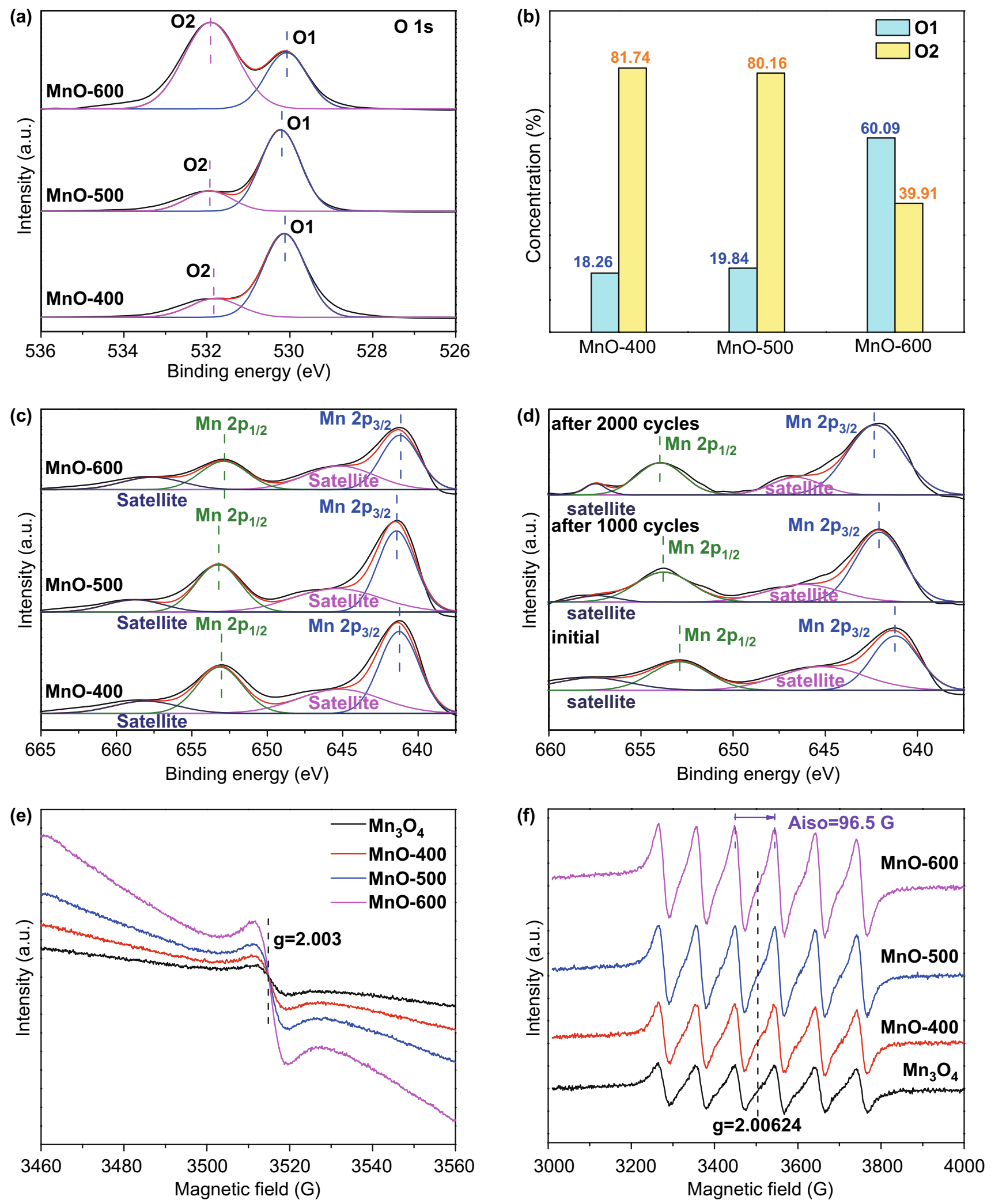

Fig. 3 a XPS O $1 s$ spectra among different MnO-T catalysts. b Contents of O1 and O2 peak for different MnO-T samples. c, d XPS Mn $2 p$ spectra of the starting MnO-T catalysts (c) and MnO-600 of the initial and after 1000 and 2000 cycles of ORR tests (d). e, f ESR measurement results of $\mathrm{Mn}_{3} \mathrm{O}_{4}$ and $\mathrm{MnO}-\mathrm{T}$ samples for oxygen vacancies detections (e) and $\mathrm{Mn}$ valence determinations (f) 


\subsection{Electrocatalytic ORR Performances}

The electrocatalytic performances of the synthesized catalysts for ORR were evaluated in $\mathrm{N}_{2}$ and $\mathrm{O}_{2}$-saturated $1 \mathrm{M}$ $\mathrm{KOH}$ solutions using a rotating disk electrode (RDE) and a rotating ring-disk electrode (RRDE) system. First, the cyclic voltammetric $(\mathrm{CV})$ measurements were conducted at a scan rate of $100 \mathrm{mV} \mathrm{s}^{-1}$ on $\mathrm{MnO}$ catalysts obtained at varied reduction temperatures to manifest the influence of sample reduction on the morphology evolution and electrochemical performance. As shown in Fig. 4a, MnO-600 exhibits a much higher electrochemical active surface area $\left(\mathrm{ECSA}=0.405 \mathrm{~cm}^{2}\right)$ and peak current density than the electrocatalysts treated at other temperatures. In the meantime, from the linear sweep voltammetric (LSV) polar curves (Fig. 4b), the MnO-600 catalyst clearly shows the highest ORR electrocatalytic activity of $0.895 \mathrm{~V}$ in its half-wave potential $\left(E_{1 / 2}\right)$, which is $18 \mathrm{mV}$ higher than that of commercial Pt/C $\left(E_{1 / 2}=0.877 \mathrm{~V}\right)$. Furthermore, the limiting current density of MnO-600 catalyst is highly comparable to that of the state-of-the-art commercial Pt/C catalysts. The specific activity at $0.89 \mathrm{~V}$ versus RHE for $\mathrm{MnO}-600$ is $1.52 \mathrm{~mA} \mathrm{~cm}^{-2}$, about 1.4 times and 4.5 times higher than that of $\mathrm{Pt} / \mathrm{C}$ and MnO-500 (Fig. S9). It can also be found that there is a downward peak at around $0.623 \mathrm{~V}$ (vs. RHE) for MnO-600 sample, which is attributed to the valence change between $\mathrm{Mn}$ (II) and $\mathrm{Mn}$ (III) under elevated potentials. The presence of $\mathrm{Mn}$ (III) is beneficial to the improvement of electrocatalytic activity and thus endows the catalyst with enhanced current density. Figure S10 displays the $\mathrm{CV}$ curves of MnO-600 sample in $\mathrm{N}_{2}$ and $\mathrm{O}_{2}$-saturated media, which shows the presence of redox peaks and further confirms oxygen reduction activity in $\mathrm{O}_{2}$-saturated electrolyte.

To assess the stability of such a simple MnO-600 catalyst, a long-term cycling test between 0.6 and $1.0 \mathrm{~V}$ (vs. RHE) was performed. It can be found from Fig. $4 \mathrm{c}$ that there is no significant decrease in the ORR electrocatalytic activity even tested for 2000, 4000 and 6000 cycles, indicating the excellent ORR catalytic stability of MnO-600 catalyst during prolonged cycling tests, and the half-wave potential value has only suffered a slight loss by $25 \mathrm{mV}$. Apparently, the downward peak at around $0.623 \mathrm{~V}$ (vs. RHE) become gradually weakened and finally disappeared during the ORR cycling tests from the initial to 6000 cycles, indicating the completed valence change of $\mathrm{Mn}$ ions from $2+$ to $3+/ 4+$, as discussed above after the long-term cycling test. To further evaluate the catalyst stability, the chronoamperometry test was also performed. Impressively, the ORR activity will experience a significant enhancement (150\% of initial current) (Fig. 4d) after the $\mathrm{MnO}$ electrocatalyst being measured for $1000 \mathrm{~s}$ under the constant applied potential $(0.7 \mathrm{~V}$ vs. RHE), which can be explained by the production of a new component $\mathrm{Mn}_{5} \mathrm{O}_{8}$ as shown in the XRD patterns (Fig. S1) from $\mathrm{MnO}$ samples discussed above. After experiencing a period of electrochemical operation, $\mathrm{Mn}$ (II) ion has been fully oxidized to $\mathrm{Mn}(\mathrm{III})$ and $\mathrm{Mn}(\mathrm{IV})$, and these in situ generated $\mathrm{Mn}^{3+}$ and $\mathrm{Mn}^{4+}$ species are the key to achieve enhanced ORR activities. After that, the catalyst keeps stable at a high current density for at least 25,000 s to the end of the test, which further proves the excellent ORR stability of MnO-600 catalyst. Meanwhile, to prove the role of oxygen vacancies in $\mathrm{MnO}$ in elevating the ORR activity and conductivity, comparisons of LSV and ESI results between MnO-600 and MnO-purchase are shown in Figs. S12 and S13. It is clear that the MnO-600 rich in oxygen vacancies exhibits much higher ORR catalytic activity than the $\mathrm{MnO}$ purchased.

Moreover, the RRDE tests of the catalysts were conducted in $\mathrm{O}_{2}$-saturated $1 \mathrm{M} \mathrm{KOH}$ solution to calculate the $\mathrm{H}_{2} \mathrm{O}_{2}$ yields and the corresponding electron transfer numbers. As shown in Fig. 4e, the $\mathrm{H}_{2} \mathrm{O}_{2}$ yield for $\mathrm{MnO}-600$ is about $10 \%$ and the corresponding electron transfer number $(n)$ is close to the theoretical value of 4 at potentials ranging from 0 to $1.0 \mathrm{~V}$ (vs. RHE), proving a four-electron transfer pathway for ORR. The corresponding ring currents, $\mathrm{H}_{2} \mathrm{O}_{2}$ yields and electron transfer numbers for the other catalysts are shown in Figs. S14-S16, respectively. For further comparison, Fig. 4f displays the $\mathrm{H}_{2} \mathrm{O}_{2}$ yield histogram and corresponding electron transfer numbers at $0.8 \mathrm{~V}$ (vs. RHE) of different catalysts. Similar to the catalytic activity discussed earlier, the MnO-600 electrocatalyst shows the lowest $\mathrm{H}_{2} \mathrm{O}_{2}$ yield and the highest electron transfer number among all samples. The results further prove that $\mathrm{MnO}-600$ electrocatalyst demonstrates better catalytic performance than the other catalysts.

The electrochemical impedance spectroscopy (EIS) measurement was conducted at $0.965 \mathrm{~V}$ (vs. RHE) and in the frequency range from $10^{-2}$ to $10^{5} \mathrm{~Hz}$ to elucidate the charge transfer resistance at the electrode surface. As shown in Fig. $4 \mathrm{~g}$ and the inset, the MnO-600 electrocatalyst shows a quite low solution resistance $\left(R_{\mathrm{S}}=5.31 \Omega\right)$ and displays the smallest semicircle diameter from Nyquist plot, indicating 

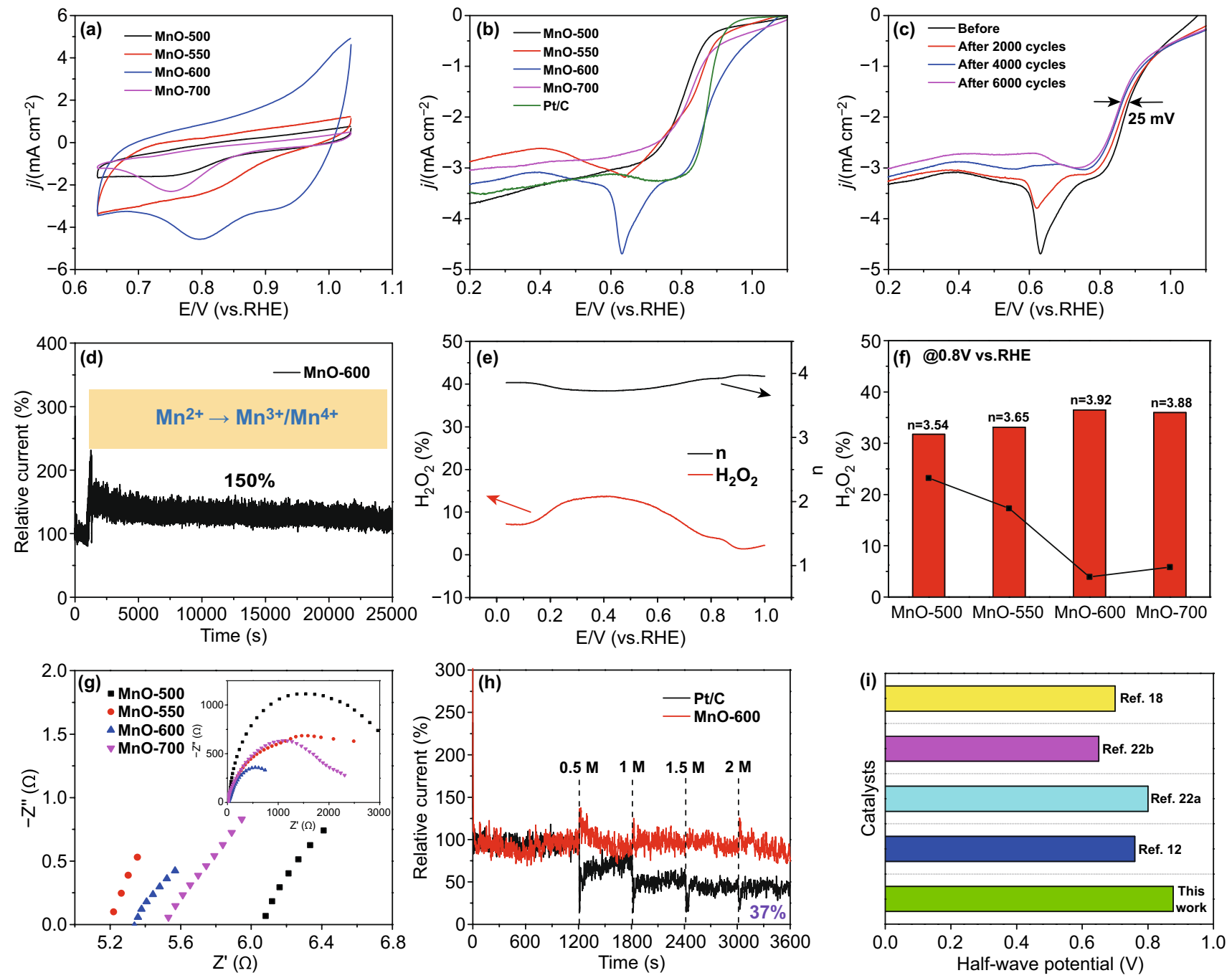

Fig. 4 ORR performances of the prepared catalysts and their comparisons in $1 \mathrm{M} \mathrm{KOH}$ solution. a CV curves of MnO-T catalysts. b LSV curves of MnO-T catalysts at a scan rate of $10 \mathrm{mV} / \mathrm{s}$. c Stability measurements for MnO-600 sample at the initial cycle and after 2000,4000 and 6000 cycles. d Time-dependent current density curve at $0.7 \mathrm{~V}$ (vs. RHE) obtained by continuous test for $25,000 \mathrm{~s}$. e $\mathrm{H}_{2} \mathrm{O}_{2}$ yields of $\mathrm{MnO}-600$ at varied potentials and the corresponding electron transfer numbers. $\mathbf{f} \mathrm{H}_{2} \mathrm{O}_{2}$ yields (dots) and the corresponding electron transfer numbers (columns) at $0.8 \mathrm{~V}$ (vs. RHE) for different catalysts. $\mathbf{g}$ Nyquist plots of the catalysts (inset: AC impedance curves of different catalysts at the potential of $0.965 \mathrm{~V}$ (vs. RHE) and in the frequency range from $10^{-2}$ to $10^{5} \mathrm{~Hz}$ ). h Tolerance measurements to methanol at $0.7 \mathrm{~V}$ (vs. RHE) for Pt/C and $\mathrm{MnO}-600$ catalysts. $\mathrm{i}$ Comparison of ORR performances among $\mathrm{MnO}_{x}$-based electrocatalysts in the alkaline electrolyte

the fastest charge transfer among all samples. Besides, the corresponding equivalence circuit for MnO-600 catalyst is shown in Fig. S17. The faster charge transfer between electrode and electrolyte results in the more significant enhancement of the catalytic activity for $\mathrm{O}_{2}$ reduction. On the whole, it is concluded that the MnO-600 electrocatalyst exhibits the most excellent ORR catalytic performance because of its lower charge transfer resistance and faster charge transfer speed.
Besides, the tolerance measurements to methanol crossover were conducted at $0.7 \mathrm{~V}$ (vs. RHE) in $1 \mathrm{M} \mathrm{O}_{2}$-saturated $\mathrm{KOH}$ solutions by the amperometric $i-t$ curves (Fig. 4h). After tested for $1200 \mathrm{~s}, 0.5 \mathrm{M}$ methanol into the electrolyte was added every $600 \mathrm{~s}$ for 4 times in all. It can be clearly seen that the current of the MnO-600 catalyst almost keeps unchanged after the additions of methanol, while the commercial Pt/C catalyst suffers substantial current density losses and remains only $37 \%$ of the initial current at the end of the tests. By comparing the ORR half-wave potentials and 
electron transfer numbers between the presently prepared MnO-600 catalyst and other $\mathrm{MnO}_{x}$-based alkaline electrocatalysts in the previous reports (Figs. 4i, S18 and Table S4) $[31,32]$, it can be found that the MnO-600 catalyst demonstrates the most excellent ORR catalytic performance.

\subsection{Zinc-Air Battery Performance}

To further demonstrate the extra-high ORR catalytic activity of the as-synthesized $\mathrm{MnO}$ (II) electrocatalyst, zinc-air batteries were assembled as exemplified in Fig. 5a, in which a carbon paper pre-coated with the ORR catalyst MnO-600, or commercial Pt/C catalyst, was used as an air cathode, in coupling with a $\mathrm{Zn}$ anode and a glassy fiber membrane soaked with aqueous $6 \mathrm{M} \mathrm{KOH}$ electrolyte as the separator. Figure $5 \mathrm{~b}$ shows the polarization and power density curves of air-breathing zinc-air battery with a working electrode area of $3 \mathrm{~cm}^{2}$ and catalyst loading amount of $2 \mathrm{mg} \mathrm{cm}^{-2}$, which were operated at room temperature of $\sim 20^{\circ} \mathrm{C}$. It can be seen that the peak current density and peak power density of $\mathrm{MnO}-600$ are as high as $102.7 \mathrm{~mA} \mathrm{~cm}{ }^{-2}$ and $63.2 \mathrm{~mW} \mathrm{~cm}^{-2}$, respectively, which are markedly higher than those of commercial Pt/C (peak current density $=69.2 \mathrm{~mA} \mathrm{~cm}^{-2}$; peak power density $=47.4 \mathrm{~mW} \mathrm{~cm}^{-2}$ ) under identical test conditions.

It can be confirmed from Fig. $5 \mathrm{c}$ that the cell voltage of MnO-600 catalyst keeps as stable as commercial $\mathrm{Pt} / \mathrm{C}$ at the relatively low applied currents in the range of 2-10 $\mathrm{mA} \mathrm{cm}^{-2}$. When the applied current density reaches $20 \mathrm{~mA} \mathrm{~cm}^{-2}$, the commercial Pt/C experiences a rapid deactivation, while MnO-600 still retains a cell voltage platform, suggesting the much better stability of MnO-600 catalyst under high current density. Moreover, durability of the batteries was further evaluated using galvanostatic recurrent pulse method at a constant current density of $10 \mathrm{~mA} \mathrm{~cm} \mathrm{~cm}^{-2}$ and a discharge/recharge cyclic duration of $10 \mathrm{~min}(5 \mathrm{~min}$ each) (Fig. 5d). It is obvious that the $\mathrm{Zn}$-air battery using MnO-600 as cathode catalyst is highly rechargeable and shows negligible voltage decay during $35 \mathrm{~h}$ of the cyclic test, which is highly comparable to that of commercial $\mathrm{Pt} / \mathrm{C}$ benchmark. As an example for practical application (Fig. 5e), multiple $\mathrm{Zn}$-air batteries were connected in series to power different light-emitting diode (2-2.2 V) and the LED display $(1.5 \mathrm{~V})$. A real-time LED video powered by $\mathrm{Zn}$-air batteries by using MnO-600 as cathode catalyst is shown in Supplement Movie. All these operations clearly demonstrate that $\mathrm{MnO}-600$ catalyst is a promising catalyst for advanced energy storage and conversion technologies.

\section{ORR Mechanism Probing}

Generally, the electrocatalytic oxygen reduction in alkaline media could proceed via either a direct four-electron pathway producing hydroxide $\left(\mathrm{OH}^{-}\right)$or a two-step (twoelectron + two-electron) pathway producing hydroperoxide $\left(\mathrm{HO}_{2}{ }^{-}\right)$groups. The detailed reaction equations are displayed in Eqs. (4)-(7) [33, 34].

$\mathrm{O}_{2}+2 \mathrm{H}_{2} \mathrm{O}+4 \mathrm{e}^{-}=4 \mathrm{OH}^{-} \quad$ (four - electron pathway)

or

$\mathrm{O}_{2}+\mathrm{H}_{2} \mathrm{O}+2 \mathrm{e}^{-}=\mathrm{HO}_{2}^{-}+\mathrm{OH}^{-} \quad$ (two - electron pathway)

$\mathrm{HO}_{2}^{-}+\mathrm{H}_{2} \mathrm{O}+2 \mathrm{e}^{-}=3 \mathrm{OH}^{-} \quad$ (two - electron pathway)

$\left(\right.$ or $\left.\mathrm{HO}_{2}^{-}=\mathrm{OH}^{-}+1 / 2 \mathrm{O}_{2}\right)$

It has been believed that pure $\mathrm{Mn}^{2+}$ or $\mathrm{Mn}^{4+}$ species are not ORR kinetic-favorable owing to the occurrence of a portion of two-electron reduction pathway. Nevertheless, the catalyst will experience an oxygen reduction pathway via a quasi-fourelectron pathway after the introduction of a small amount of $\mathrm{Mn}^{3+}$ [35]. However, $\mathrm{Mn}^{3+}$ would be unlikely to exist stably due to the inevitable Jahn-Teller distortion [36]. According to the Jahn-Tell effect, unstable $\mathrm{Mn}^{3+}$ will be disproportionated to $\mathrm{Mn}^{2+}$ and $\mathrm{Mn}^{4+}\left(2 \mathrm{Mn}^{3+}=\mathrm{Mn}^{2+}+\mathrm{Mn}^{4+}\right)$ at $\mathrm{pH}<9$ [37]. In this study, $\mathrm{Mn}^{3+}$ was in situ generated which could exist stably in $1 \mathrm{M} \mathrm{KOH}$ solutions $(\mathrm{pH}=14)$ via the electrochemical method under the constant applied potential.

Besides the effect on electron transfer number, the nonnegligible role of $\mathrm{Mn}^{3+}$ in ORR catalysis can also be found on facilitating the interaction between the electronic structure and absorbed oxygen. The coexistence of $\mathrm{Mn}^{3+}$ and $\mathrm{Mn}^{4+}$ has been reported to promote the cleavage of $\mathrm{O}-\mathrm{O}$ bonds and thus ensures the rapid reduction of $\mathrm{O}_{2}$ to $\mathrm{OH}^{-}$. The trivalent $\mathrm{Mn}$ ion adopts a high-spin $\mathrm{d}^{4}$ configuration $\left(\mathrm{t}_{2 \mathrm{~g}}^{3} \mathrm{e}_{\mathrm{g}}^{1}\right)$ [38], whereas the produced $\mathrm{Mn}^{2+}$ and $\mathrm{Mn}^{4+}$ (due to the charge disproportionation of $\mathrm{Mn}^{3+}$ ) possess non-degenerated $\mathrm{t}_{2 \mathrm{~g}}^{3} \mathrm{e}_{\mathrm{g}}^{2}$ and $\mathrm{t}_{2 \mathrm{~g}}^{3} \mathrm{e}_{\mathrm{g}}^{0}$ configurations, respectively (Fig. 6a) [37]. In a truncated octahedral environment, the antibonding orbitals of $\mathrm{Mn}^{3+}$ will overlap directly with that of top-absorbed $\mathrm{O}$ species thus to influence 
(a)

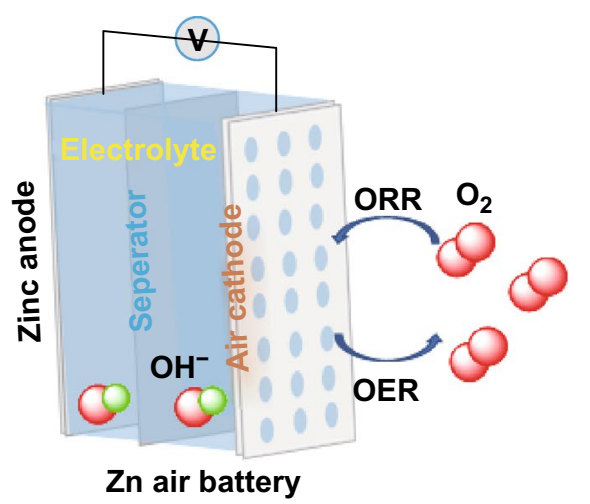

(c)

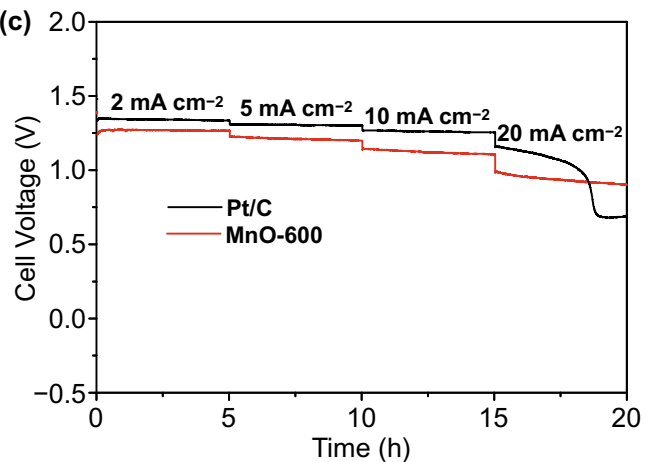

(e)

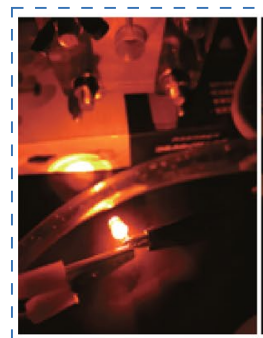

Red

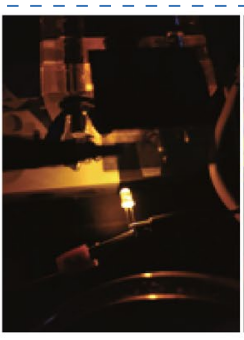

Yellow

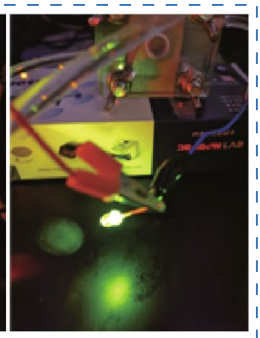

Green
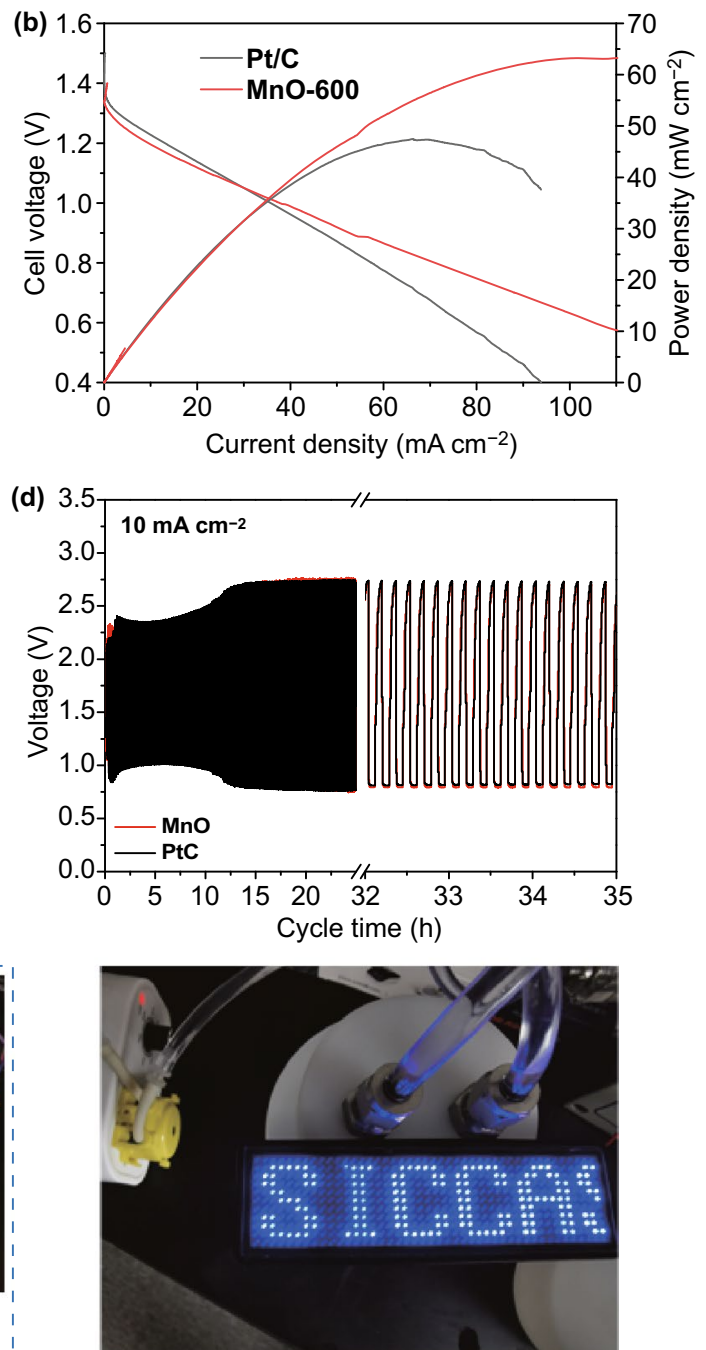

Fig. 5 a Schematics of the primary configuration of a Zn-air battery. b Polarization curves of zinc-air battery based on MnO-600 or commercial Pt/C catalyst as cathode: cathode area: $3 \mathrm{~cm}^{2}$; loading amount: $2 \mathrm{mg} \mathrm{cm}^{-2}$; temperature: $\sim 20{ }^{\circ} \mathrm{C}$; $\mathbf{c}$ longtime durability of zinc-air battery by using MnO-600 or commercial Pt/C as cathode catalyst at the current densities of 2, 5, 10 and $20 \mathrm{~mA} \mathrm{~cm}^{-2}$. d Galvanostatic discharge-charge cycling curve at $10 \mathrm{~mA} \mathrm{~cm}{ }^{-2}$ of the zinc-air battery using MnO-600 or Pt/C catalyst. e Photographs of different light-emitting diode (1.5 V, $2-2.2 \mathrm{~V})$

the bonding strength of $\mathrm{O}_{2}$ onto $\mathrm{Mn}^{3+}$ via the filling status (Fig. 6b) [19]. According to the wildly accepted four-step proton-coupled electron transfer reaction mechanism (Fig. 6c), the four-electron process for the ORR catalyzed by $\mathrm{MnO}_{x}$ can be schemed as [39]: (1) $\mathrm{O}_{2}$ is absorbed and transformed into $\mathrm{OO}_{2}{ }^{-}$on a $\mathrm{Mn}$ site by displacing the $\mathrm{OH}^{-}$group originally adhered on the catalyst surface in the alkaline solution; (2) the $\mathrm{OO}_{2}^{-}$group is protonated to form $\mathrm{OOH}^{-}$; (3) an $\mathrm{OH}^{-}$group is removed from $\mathrm{OOH}^{-}$, leaving a superoxo $\mathrm{O}_{2}{ }^{-}$group on the previous Mn site; (4) the $\mathrm{O}_{2}^{-}$group is again protonated to form $\mathrm{OH}^{-}$thus to rebuild the initial hydroxyl-covered surface of $\mathrm{MnO}_{x}$. This is a complete cycle of ORR accompanying the reversible component change on the $\mathrm{MnO}_{x}$ catalyst surface during the oxygen reduction. The corresponding reactions are formulated as follows:

$\mathrm{O}_{2}+\mathrm{Mn}-\mathrm{OH}+\mathrm{e}^{-}=\mathrm{Mn}-\mathrm{OO}^{*}+\mathrm{OH}^{-}$

$\mathrm{Mn}-\mathrm{OO}^{*}+\mathrm{H}_{2} \mathrm{O}+\mathrm{e}^{-}=\mathrm{Mn}-\mathrm{OOH}+\mathrm{OH}^{-}$

$\mathrm{Mn}-\mathrm{OOH}+\mathrm{e}^{-}=\mathrm{Mn}-\mathrm{O}+\mathrm{OH}^{-}$

$\mathrm{Mn}-\mathrm{O}+\mathrm{H}_{2} \mathrm{O}+\mathrm{e}^{-}=\mathrm{Mn}-\mathrm{OH}+\mathrm{OH}^{-}$ 
From the four ORR steps taking place on the $\mathrm{MnO}$, i.e., the oxygen adsorption to replace $\mathrm{OH}^{-}$group at the $\mathrm{Mn}$ site (step 1) is regarded as the rate-determining step in the ORR kinetics on metal oxides. On the one hand, the synthesized MnO-600 catalyst possesses the largest amount of oxygen vacancies in the prepared materials according to the XPS O1s spectra and ESR result, and thus, the presence of oxygen vacancies will accelerate the adsorption of $\mathrm{O}_{2}$ molecules to promote step (1), resultantly facilitating the ORR activity elevation. On the other hand, the in situ generated large quantity of $\mathrm{Mn}^{3+}$ ions during the electrochemical test of $\mathrm{MnO}$ will lead to much weakened oxygen adsorption because of the existence of electron in the orbitals of $\mathrm{Mn}^{3+}$, thus favoring the cleavage/desorption of $\mathrm{OH}^{-}$groups from the Mn sites and accelerating the steps (1) to (4), consequently resulting in largely enhanced ORR kinetics.

In addition, $\mathrm{Mn}^{4+}$ is proved to be highly active for peroxide decomposition [40]. The in situ generated $\mathrm{Mn}^{4+}$ species in $\mathrm{Mn}_{5} \mathrm{O}_{8}$ of MnO-600 catalyst will facilitate the reaction (10) and accelerate the ORR process during the electrochemical tests. Thus, the excellent ORR performance of synthesized MnO-600 can be attributed to the synergistic catalytic effect among the presence of oxygen vacancies and the in situ generated $\mathrm{Mn}^{3+}$ and $\mathrm{Mn}^{4+}$ species, in which the oxygen vacancies accelerate the adsorption of $\mathrm{O}_{2}$ molecules,
$\mathrm{Mn}^{3+}$ catalyze ORR and $\mathrm{Mn}^{4+}$ catalyze peroxide decomposition in a synergetic way, i.e., the oxygen vacancies, $\mathrm{Mn}^{3+}$ and $\mathrm{Mn}^{4+}$ ions function successively in the ORR catalysis [41], resulting in overall enhanced ORR catalytic activity.

\section{Conclusion}

A simple noble metal-free $\mathrm{Mn}$ (II)O electrocatalyst with excellent ORR performance has been fabricated via a facile "two-step" strategy. The excellent ORR electrocatalytic performance has been obtained on the $\mathrm{MnO}$ catalyst synthesized by heat-reducing the starting $\mathrm{Mn}_{3} \mathrm{O}_{4}$ at $600{ }^{\circ} \mathrm{C}$, which exhibits a half-wave potential $\left(E_{1 / 2}\right)$ of as high as $0.895 \mathrm{~V}$, $18 \mathrm{mV}$ higher than that of commercial Pt/C $\left(E_{1 / 2}=0.877 \mathrm{~V}\right)$. Besides, the marked $\mathrm{Zn}$-air battery performances in terms of peak current density, peak power density and durability have been achieved by using the MnO-600 as the cathode electrocatalyst. More impressively, the ORR activity can be significantly enhanced during the long-term electrochemical test owing to the in situ generation and stable existence of higher valence manganese ions in the form of $2 \mathrm{Mn}_{2} \mathrm{O}_{3} \cdot \mathrm{MnO}_{2}$. According to the mechanism analysis for the ORR reaction pathway, a synergetic catalytic effect has been proposed, in which the oxygen vacancies, and in situ (a)

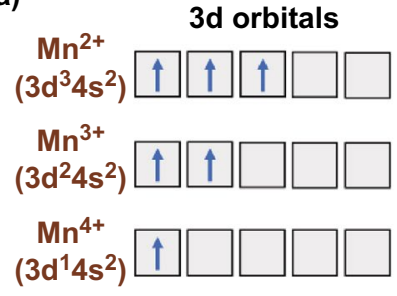

(b) $\mathrm{OH}^{-}$

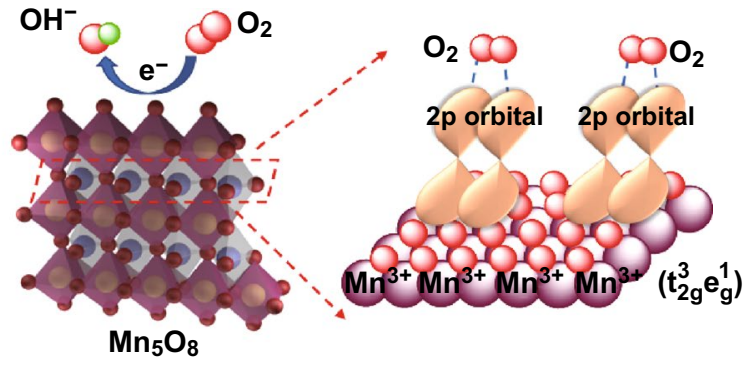

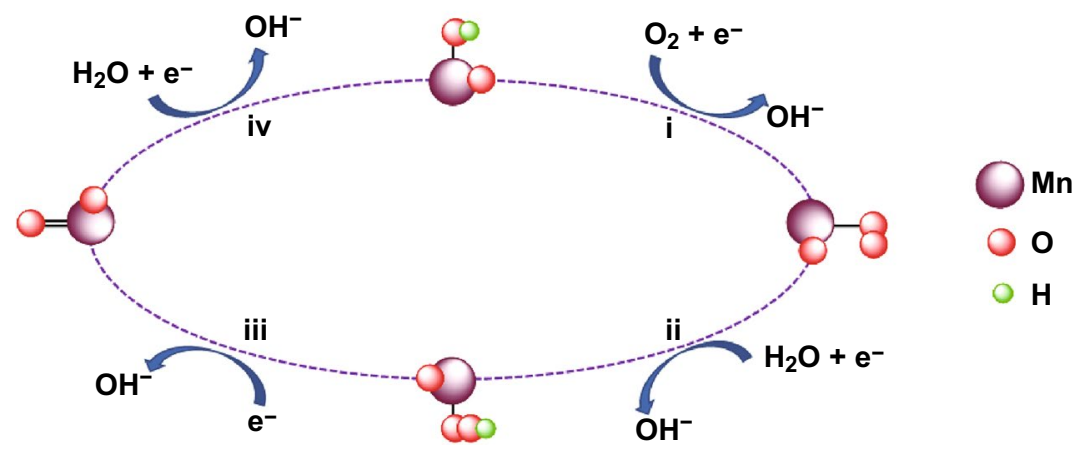

Fig. 6 a Occupied states of $3 d$ orbitals for $\mathrm{Mn}^{2+}, \mathrm{Mn}^{3+}$ and $\mathrm{Mn}^{4+}$. b Lattice structure of $\mathrm{Mn}_{5} \mathrm{O}_{8}$ (yellow: $\mathrm{Mn}^{4+} ;$ blue: $\mathrm{Mn}^{3+}$ ) and the ball-stick model of the $\mathrm{O}_{2}$ molecule adsorptions on the surface. c Possible four-electron reaction mechanism for $\mathrm{MnO}_{x}$ in ORR process 
generated $\mathrm{Mn}^{3+}$ and $\mathrm{Mn}^{4+}$ species function successively in the ORR catalysis, resulting in the much enhanced catalytic activity. This work not only broadens our horizon for constructing high-performance noble metal-free electrocatalyst by employing multivalence transition metal oxides, but also provides an in-depth mechanistic probing on the relationship between $\mathrm{Mn}$ valence and electrochemical performance.

Acknowledgements The authors gratefully acknowledge the support of this research by Natural Science Foundation of Shanghai (19ZR1479400), the State Key Laboratory for Modification of Chemical Fibers and Polymer Materials, Donghua University (KF1818) and the State Key Laboratory of Advanced Technology for Materials Synthesis and Processing (Wuhan University of Technology).

Open Access This article is licensed under a Creative Commons Attribution 4.0 International License, which permits use, sharing, adaptation, distribution and reproduction in any medium or format, as long as you give appropriate credit to the original author(s) and the source, provide a link to the Creative Commons licence, and indicate if changes were made. The images or other third party material in this article are included in the article's Creative Commons licence, unless indicated otherwise in a credit line to the material. If material is not included in the article's Creative Commons licence and your intended use is not permitted by statutory regulation or exceeds the permitted use, you will need to obtain permission directly from the copyright holder. To view a copy of this licence, visit http://creativecommons.org/licenses/by/4.0/.

Electronic supplementary material The online version of this article (https://doi.org/10.1007/s40820-020-00500-7) contains supplementary material, which is available to authorized users.

\section{References}

1. L. Chong, J. Wen, J. Kubal, F. Sen, J. Zou et al., Ultralowloading platinum-cobalt fuel cell catalysts derived from imidazolate frameworks. Science 362(6420), 1276-1281 (2018). https://doi.org/10.1126/science.aau0630

2. X. Wan, X. Liu, Y. Li, R. Yu, L. Zheng et al., Fe-N-C electrocatalyst with dense active sites and efficient mass transport for high-performance proton exchange membrane fuel cells. Nat. Catal. 2, 259-268 (2019)

3. J. Zhang, Z. Zhao, Z. Xia, L. Dai, A metal-free bifunctional electrocatalyst for oxygen reduction and oxygen evolution reactions. Nat. Nanotech. 10, 444-452 (2015). https://doi. org/10.1038/NNANO.2015.48

4. F. Kong, X. Fan, A. Kong, Z. Zhou, X. Zhang, Y. Shan, Covalent phenanthroline framework derived $\mathrm{FeS} @ \mathrm{Fe}_{3} \mathrm{C}$ composite nanoparticles embedding in $\mathrm{N}-\mathrm{S}$-codoped carbons as highly efficient trifunctional electrocatalysts. Adv. Funct. Mater. 28(51), 1803973 (2018). https://doi.org/10.1002/adfm.20180 3973
5. M. Xiao, J. Zhu, L. Feng, C. Liu, W. Xing, Meso/macroporous nitrogen-doped carbon architectures with iron carbide encapsulated in graphitic layers as an efficient and robust catalyst for the oxygen reduction reaction in both acidic and alkaline solutions. Adv. Mater. 27(15), 2521-2527 (2015). https://doi. org/10.1002/adma.201500262

6. P. Yu, L. Wang, F. Sun, Y. Xie, X. Liu et al., Co Nanoislands rooted on $\mathrm{Co}-\mathrm{N}-\mathrm{C}$ nanosheets as efficient oxygen electrocatalyst for Zn-air batteries. Adv. Mater. 31, 1901666 (2019). https ://doi.org/10.1002/adma.201901666

7. X. Liu, L. Wang, P. Yu, C. Tian, F. Sun et al., A stable bifunctional catalyst for rechargeable zinc-air batteries: iron-cobalt nanoparticles embedded in a nitrogen-doped 3D carbon matrix. Angew. Chem. Int. Ed. 57(49), 16166-16170 (2018). https://doi.org/10.1002/anie.201809009

8. X. Tian, X. Zhao, Y. Su, L. Wang, H. Wang et al., Engineering bunched Pt-Ni alloy nanocages for efficient oxygen reduction in practical fuel cells. Science 366(6467), 850-856 (2019). https://doi.org/10.1126/science.aaw7493

9. Q. Qin, H. Jang, P. Li, B. Yuan, X. Liu, J. Cho, A tannic acid-derived N-, P-codoped carbon-supported iron-based nanocomposite as an advanced trifunctional electrocatalyst for the overall water splitting cells and zinc-air batteries. Adv. Energy Mater. 9(5), 1803312 (2019). https://doi.org/10.1002/ aenm.201803312

10. P. Li, H. Jang, J. Zhang, M. Tian, S. Chen et al., A metal-free $\mathrm{N}$ and P-codoped carbon nanosphere as bifunctional electrocatalyst for rechargeable zinc-air batteries. ChemElectroChem 6(2), 393-397 (2019). https://doi.org/10.1002/celc.201801419

11. Y. Nie, L. Li, Z. Wei, Recent advancements in Pt and Pt-free catalysts for oxygen reduction reaction. Chem. Soc. Rev. 44(8), 2168-2201 (2015). https://doi.org/10.1039/c4cs00484a

12. A. Bhargava, C. Chen, K. Dhaka, Y. Yao, A. Nelson et al., $\mathrm{Mn}$ cations control electronic transport in spinel $\mathrm{Co}_{x} \mathrm{Mn}_{3-x} \mathrm{O}_{4}$ nanoparticles. Chem. Mater. 31(11), 4228-4233 (2019). https ://doi.org/10.1021/acs.chemmater.9b01198

13. X. Ge, A. Sumboja, D. Wuu, T. An, B. Li et al., Oxygen reduction in alkaline media: from mechanisms to recent advances of catalysts. ACS Catal. 5(8), 4643-4667 (2015). https://doi.org/10.1021/acscatal.5b00524

14. S. Lee, G. Nam, J. Sun, J.S. Lee, H.W. Lee et al., Enhanced intrinsic catalytic activity of $\lambda-\mathrm{MnO}_{2}$ by electrochemical tuning and oxygen vacancy generation. Angew. Chem. Int. Ed. 55(30), 8599-8604 (2016). https://doi.org/10.1002/anie.201602851

15. Y. Huang, J. Mou, W. Liu, X. Wang, L. Dong, F. Kang, C. $\mathrm{Xu}$, Novel insights into energy storage mechanism of aqueous rechargeable $\mathrm{Zn} / \mathrm{MnO}_{2}$ batteries with participation of $\mathrm{Mn}^{2+}$. Nano-Micro Lett. 11, 49 (2019). https://doi. org/10.1007/s40820-019-0278-9

16. D.M. Robinson, Y.B. Go, M. Mui, G. Gardner, Z. Zhang et al., Photochemical water oxidation by crystalline polymorphs of manganese oxides: structural requirements for catalysis. J. Am. Chem. Soc. 135, 3494-3501 (2013). https ://doi.org/10.1021/ja310286h

17. M. Asif, A. Aziz, A. Dao, A. Hakeem, H. Wang et al., Real-time tracking of hydrogen peroxide secreted by live 
cells using $\mathrm{MnO}_{2}$ nanoparticles intercalated layered doubled hydroxide nanohybrids. Anal. Chim. Acta 898, 34-41 (2015). https://doi.org/10.1016/j.aca.2015.09.053

18. S. Geller, Structures of $\alpha-\mathrm{Mn}_{2} \mathrm{O}_{3},\left(\mathrm{Mn}_{0.983} \mathrm{Fe}_{0.017}\right)_{2} \mathrm{O}_{3}$ and $\left(\mathrm{Mn}_{0.37} \mathrm{Fe}_{0.63}\right)_{2} \mathrm{O}_{3}$ and relation to magnetic ordering. Acta Crystallogr. B 21, 821-828 (1971). https://doi.org/10.1107/ S0567740871002966

19. K.A. Stoerzinger, M. Risch, B. Han, Y. Shao-Horn, Recent insights into manganese oxides in catalyzing oxygen reduction kinetics. ACS Catal. 5(10), 6021-6031 (2015). https:// doi.org/10.1021/acscatal.5b01444

20. Y. Meng, W. Song, H. Huang, Z. Ren, S.Y. Chen, S.L. Suib, Structure-property relationship of bifunctional $\mathrm{MnO}_{2}$ nanostructures: highly efficient, ultra-stable electrochemical water oxidation and oxygen reduction reaction catalysts identified in alkaline media. J. Am. Chem. Soc. 136(32), 11452-11464 (2014). https://doi.org/10.1021/ja505186m

21. H. Tian, X. Cui, L. Zeng, L. Su, Y. Song, J. Shi, Oxygen vacancy-assisted hydrogen evolution reaction of the $\mathrm{Pt} / \mathrm{WO}_{3}$ electrocatalyst. J. Mater. Chem. A 7(11), 6285-6293 (2019). https://doi.org/10.1039/c8ta12219a

22. A. Aziz, M. Asif, M. Azeem, G. Ashraf, Z. Wang, F. Xiao, H. Liu, Self-stacking of exfoliated charged nanosheets of LDHs and graphene as biosensor with real-time tracking of dopamine from live cells. Anal. Chim. Acta 1047, 197-207 (2019). https://doi.org/10.1016/j.aca.2018.10.008

23. M. Asif, A. Aziz, G. Ashraf, Z. Wang, J. Wang et al., Facetinspired core-shell gold nanoislands on metal oxide octadecahedral heterostructures: high sensing performance toward sulfide in biotic fluids. ACS Appl. Mater. Interfaces 10, 36675-36685 (2018). https://doi.org/10.1021/acsam i. 8 b 12186

24. Y. Liu, Y. Ying, L. Fei, Y. Liu, Q. Hu et al., Valence engineering via selective atomic substitution on tetrahedral sites in spinel oxide for highly enhanced oxygen evolution catalysis. J. Am. Chem. Soc. 141(20), 8136-8145 (2019). https://doi. org/10.1021/jacs.8b13701

25. H.R. Oswald, Crystal data of $\mathrm{Mn}_{5} \mathrm{O}_{8}$ and $\mathrm{Cd}_{2} \mathrm{Mn}_{3} \mathrm{O}_{8}$. Nature 207, 72 (1965)

26. Y. Gorlin, C.J. Chung, D. Nordlund, B.M. Clemens, T.F. Jaramillo, $\mathrm{Mn}_{3} \mathrm{O}_{4}$ supported on glassy carbon: an active nonprecious metal catalyst for the oxygen reduction reaction. ACS Catal. 2(12), 2687-2694 (2012). https://doi.org/10.1021/cs300 4352

27. Y. Choi, D. Lim, E. Oh, C. Lim, S.H. Baeck, Effect of proton irradiation on electrocatalytic properties of $\mathrm{MnO}_{2}$ for oxygen reduction reaction. J. Mater. Chem. A 7(19), 11659-11664 (2019). https://doi.org/10.1039/C9TA03879E

28. X. Shan, D.S. Charles, Y. Lei, R. Qiao, G. Wang et al., Bivalence $\mathrm{Mn}_{5} \mathrm{O}_{8}$ with hydroxylated interphase for high-voltage aqueous sodium-ion storage. Nat. Commun. 7, 13370 (2016). https://doi.org/10.1038/ncomms 13370

29. J. Wan, W. Chen, C. Jia, L. Zheng, J. Dong et al., Defect effects on $\mathrm{TiO}_{2}$ nanosheets: stabilizing single atomic site $\mathrm{Au}$ and promoting catalytic properties. Adv. Mater. 30(11), 1705369 (2018). https://doi.org/10.1002/adma.201705369
30. G. Er, S. Ishida, N. Takeuchi, Investigations of the electrical property, diffuse reflectance and ESR spectra of the $\mathrm{La}-(\mathrm{Fe}, \mathrm{Mn})$-codoped PTCR $\mathrm{BaTiO}_{3}$ annealed in reducing atmosphere. J. Mater. Sci. 34, 4265-4270 (1999). https://doi. org/10.1023/A:1004659004372

31. B. Kang, X. Jin, S.M. Oh, S.S.B. Patil, M.G. Kim, S.H. Kim, S.J. Hwang, An effective way to improve bifunctional electrocatalyst activity of manganese oxide via control of bond competition. Appl. Catal. B 236, 107-116 (2018). https://doi. org/10.1016/j.apcatb.2018.05.010

32. X. Cui, Z. Hua, L. Chen, X. Zhang, H. Chen, J. Shi, Manganese oxide nanorod-decorated mesoporous ZSM-5 composite as a precious-metal-free electrode catalyst for oxygen reduction. Chemsuschem 9(9), 1010-1019 (2016). https://doi. org/10.1002/cssc. 201600012

33. W.T. Hong, M. Risch, K.A. Stoerzinger, A. Grimaud, J. Suntivich, Y. Shao-Horn, Toward the rational design of nonprecious transition metal oxides for oxygen electrocatalysis. Energy Environ. Sci. 8(5), 1404-1427 (2015). https://doi. org/10.1039/c4ee03869j

34. D.W. Wang, D. Su, Heterogeneous nanocarbon materials for oxygen reduction reaction. Energy Environ. Sci. 7(2), 576-591 (2014). https://doi.org/10.1039/c3ee43463j

35. B. Zhang, H. Chen, Q. Daniel, B. Philippe, F. Yu et al., Defective and "c-disordered" hortensia-like layered $\mathrm{MnO}_{x}$ as an efficient electrocatalyst for water oxidation at neutral $\mathrm{pH}$. ACS Catal. 7(9), 6311-6322 (2017). https://doi.org/10.1021/acsca tal. $7 \mathrm{~b} 00420$

36. Q. Zhang, C. Didier, W.K. Pang, Y. Liu, Z. Wang et al., Structural insight into layer gliding and lattice distortion in layered manganese oxide electrodes for potassium-ion batteries. Adv. Energy Mater. 9(30), 1900568 (2019). https://doi.org/10.1002/ aenm.201900568

37. T. Takashima, K. Hashimoto, R. Nakamura, Inhibition of charge disproportionation of $\mathrm{MnO}_{2}$ electrocatalysts for efficient water oxidation under neutral conditions. J. Am. Chem. Soc. 134(44), 18153-18156 (2012). https://doi.org/10.1021/ ja306499n

38. N. Sakai, T. Sasaki, Photocurrent generation from semiconducting manganese oxide nanosheets in response to visible light. J. Phys. Chem. B 109, 9651-9655 (2005). https://doi. org/10.1021/jp0500485

39. J. Suntivich, H.A. Gasteiger, N. Yabuuchi, H. Nakanishi, J.B. Goodenough, Y. Shao-Horn, Design principles for oxygenreduction activity on perovskite oxide catalysts for fuel cells and metal-air batteries. Nat. Chem. 3(7), 546-550 (2011). https://doi.org/10.1038/NCHEM.1069

40. D. Chinnadurai, M. Nallal, H. Kim, O. Li, K. Park, K. Prabakar, $\mathrm{Mn}^{3+}$ active surface site enriched manganese phosphate nano-polyhedrons for enhanced bifunctional oxygen electrocatalyst. Chemcatchem 12, 1-9 (2020). https://doi. org/10.1002/cctc. 202000164

41. J. Shi, On the synergetic catalytic effect in heterogeneous nanocomposite catalysts. Chem. Rev. 113(3), 2139-2181 (2013). https://doi.org/10.1021/cr3002752 